\section{The Sunshine Act: Not a good guy versus bad guy issue}

\section{S. Larry Goldenberg, CM, OBC, MD, FRCSC}

Department of Urologic Sciences, University of British Columbia, Vancouver, BC

Cite as: Can Urol Assoc J 2014;8(1-2):18. http://dx.doi.org/10.5489/cuaj.1929

Published online February 10, 2014.

Pens, post-its, staplers, notebooks, umbrellas, meals, rounds of golf, celebrity autographs, and so on-for many years, industry lavished physicians and other healthcare providers with giveaways. Recipients viewed them simply as gifts, courtesies or gratuities, but definitely not incentives to reciprocate. We all believed that we were immune to this influence and that it did not influence our primary responsibility as patient advocates. Yet, social scientists have clearly demonstrated that the impulse to reciprocate for even small gifts is a powerful influence on people's behaviour ${ }^{1}$-and there is no data to suggest that physicians are immune to normal human behavioural responses!

We can do without the freebies. Indeed, we should. But without partnerships with industry, we would impoverish research initiatives that ultimately save lives. There is a balance to be struck, and disclosure rules that promote transparency point the way.

As the years have passed, the number of drug and device companies has increased, and so has the competition between them. Since a corporation is primarily accountable to its shareholders, its representatives who need to sell their products will tend to fall back on proven ways of influencing physicians. ${ }^{2}$ So it should be no surprise that, as the pressure on industry representatives to sell, sell, sell has intensified, so have measures to mitigate the impact of their efforts on patient care. Hence the new "sunshine laws" in the United States and, in Canada, University Policies on Conflict of Interest, Conflict of Commitment, CME guidelines, Medical Association Codes of Ethics, Standards of Industry in Medical Education and Rules regarding Relationships with Industry. These policies all intend to ensure that physicians' only objective-conscious or subconscious-is to advance the health of our patients, not the private interests of health professionals, industry or any other third party.

This is not a good guy versus bad guy issue. Industry is not our enemy, but a great friend. There are huge benefits of working together, with appropriate (but not overly excessive) oversight. Industry-funded, contract-based, yet scientifically unbiased research in academic centres will result in the development of exciting new drugs and innovative technologies. We should not fear sunshine-it is, after all, the best disinfectant-but we can embrace transparency without compromising productive partnerships in the public interest; we should be sure not to throw the baby out with the (logo-embossed) bath towel.

Competing interests: Dr. Goldenberg has received honoraria from Abbott Canada, Amgen, Astellas Pharma, and Lilly Canada in the past 2 years.

\section{References}

1. Katz D, Caplan AL, Merz JF. All gifts large and small: toward an understanding of the ethics of pharmaceutical industry gift-giving. Am J Bioeth 2003;3:39-46.

2. Fugh-Berman A, Ahari S. Following the script: How drug reps make friends and influence doctors. PloS Med 2007:4:e150

Correspondence: Dr. S. Larry Goldenberg, Diamond Healthcare Centre, Level 6 - 2775 Laurel St., Vancouver, BC V5Z 1M9; goldenb@me.com

\section{Relationships with industry: A fine balance}

\section{Gerry Brock, MD, FRCSC}

Division of Urology, Western University, London, ON

Cite as: Can Urol Assoc J 2014;8(1-2):18-9. http://dx.doi.org/10.5489/cuaj.1931

Published online February 10, 2014.

In Dr. Koyle's editorial, he eloquently describes the excesses and inappropriate relationships that have existed between some physicians and elements within the pharmaceutical industry, which in part prompted new legislation in the United States. While I won't dispute that indiscretions occurred or that greater oversight and transparency are warranted, I don't want the baby to be thrown out with the bathwater.

The current relationship that exists between clinicians, with firsthand knowledge of efficacy and safety of novel therapeutics, and pharmaceutical companies, which discover and develop these agents, is fundamental to innovation and progress. If clinical experts are not allowed to gain exposure to new drugs and devices or present their experience in sponsored events, how will physicians learn about these advances? Journal articles? Annual Society unsponsored meetings? Webcasts from the pharmaceutical company itself?

Clearly there is a need for physicians to provide credible, evidence-based information on drugs and devices to physi- 